\title{
Pathophysiology of Lipoprotein Oxidation
}

\author{
Vikram Jairam, Koji Uchida and Vasanthy Narayanaswami
}

Additional information is available at the end of the chapter

http://dx.doi.org/10.5772/50622

\section{Introduction}

Lipoproteins are large lipid/protein complexes that play a major role in transport of lipids and lipophilic molecules in the plasma and central nervous system (CNS). Plasma lipoproteins represent a dynamic continuum of particles that are constantly undergoing remodulation in their lipid and protein components leading to re-structuring of the particle under normal physiological conditions. The re-modulation is the result of lipid transfer and metabolism mediated by non-enzymatic and enzymatic processes, and of lipid association/dissociation behavior of apolipoproteins. Variations in protein and lipid components and composition arise because of changes in the feeding, metabolic and hormonal states, and due to differences in age, gender and disease states.

In this chapter, we will focus on oxidation of lipoproteins, paying attention to sources of oxidative stress, oxidation products of specific lipid and protein components, and the pathophysiology of oxidized lipoproteins in various disease states. The disease states that are addressed in this chapter include cardiovascular disease (CVD)/atherosclerosis, Alzheimer's disease and diabetes.

\section{Lipoproteins}

\subsection{Classes of lipoproteins in plasma and CNS}

Lipoproteins are classified based on their density, ranging from high density lipoproteins (HDL), low density lipoproteins (LDL), intermediate density lipoproteins (IDL), very low density lipoproteins (VLDL) and, chylomicrons (CM), Figure 1. They can also be classified based on their mobility during electrophoresis on an agarose gel as $\alpha$-, pre- $\beta$ - and $\beta$ lipoproteins, which correspond to HDL, VLDL and LDL, respectively. Lipoproteins vary significantly in particle diameter and density, protein and lipid components and composition. In general, the particle diameter is inversely related to the density. 


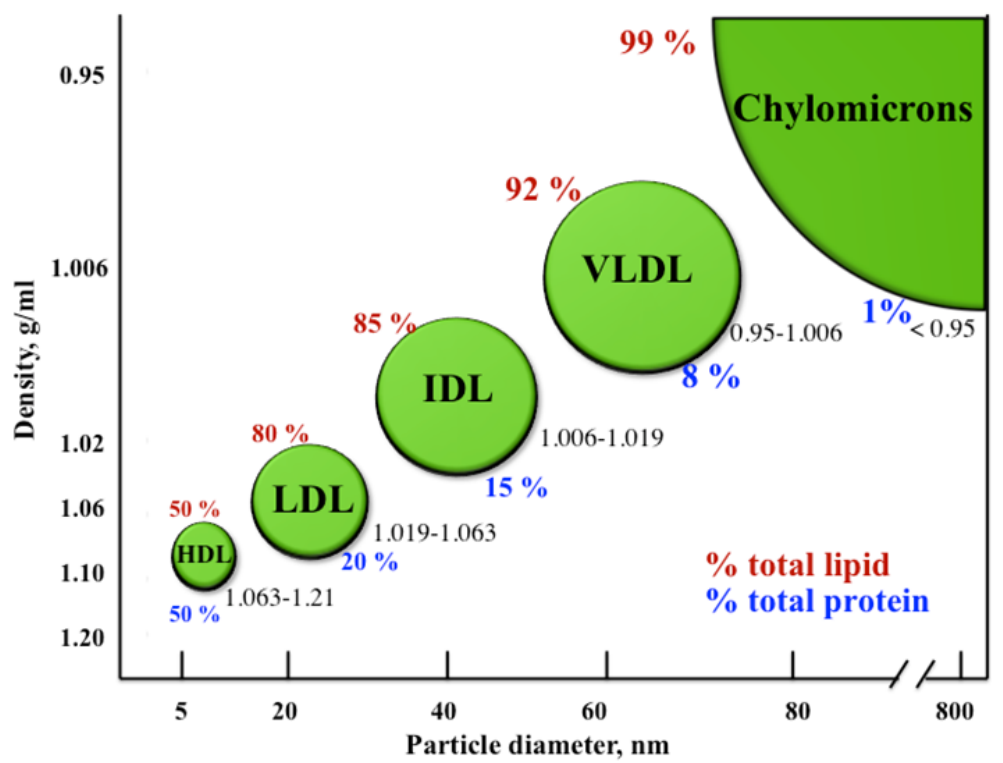

Figure 1. Lipoprotein classes. The classification of the major types of lipoproteins is based on their densities obtained by flotation ultracentrifugation analysis. The density range for each class is shown, in addition to the lipid (red) and protein (blue) content. The diagram is not to scale.

One of the main functions of lipoproteins is to transport hydrophobic factors in the highly aqueous vascular system. The CM is composed of lipids of dietary origin and is synthesized by the intestines. The VLDL is synthesized and secreted by the liver, and plays a role in distribution of lipids synthesized by the liver to the peripheral tissues. In the blood stream, the VLDL undergoes particle re-modulation to IDL and LDL, during which process the LDL become enriched in cholesterylesters. LDL plays a predominant role in delivery of cholesterol to the peripheral tissues and to the liver, with the cell surface-localized LDL receptor (LDLr) family of proteins playing a role in the cellular uptake and internalization of lipoproteins in target cells. The HDL may be synthesized by the liver and intestines or derived from other lipoproteins. In addition, peripheral tissues such as the macrophages are an important source of HDL, which are formed from cellular cholesterol efflux, and eventually transported to the liver. This process is called reverse cholesterol transport (RCT), which is an important mechanism for removal of peripheral cholesterol to the liver for eventual disposal.

Much less is known about lipoprotein metabolism in the CNS. Studies on lipoproteins secreted by astrocytes and those isolated from the cerebrospinal fluid (CSF) indicate the presence of only HDL-sized particles; large triglyceride-containing lipoprotein particles have not been detected in the CNS. The CNS maintains autonomy in terms of cholesterol synthesis and metabolism, right from the time when the blood brain barrier is established during development. One of the main functions of HDL secreted by astrocytes appears to be cholesterol delivery to the neurons via the LDLr family of proteins, for eventual use in the process of synaptogenesis. 


\subsection{Lipid and protein components of lipoproteins}

In general lipoproteins are spherical in shape with a monolayer of amphipathic lipids (for example phospholipids, cholesterol and sphingolipids) and proteins encircling a core of neutral lipids (such as triglycerides and cholesterylesters), Figure 2. The lipid composition and content vary significantly in the different lipoproteins: in general, the larger lipoproteins (CM, VLDL and IDL) are enriched in triglycerides, while the smaller lipoproteins (LDL and HDL) are enriched in cholesterylesters and cholesterol. Unesterified or free cholesterol is esterified to cholesterylester by the action of lecithin-cholesterol acyltransferase (LCAT) on HDL. The phospholipids serve as the donor of the fatty acyl chains (especially 18:1 or 18:2 fatty acids) utilized in the esterification process. The fatty acid composition of triglycerides in the fasted state is dominated by $16: 0$ and 18:1 fatty acids.

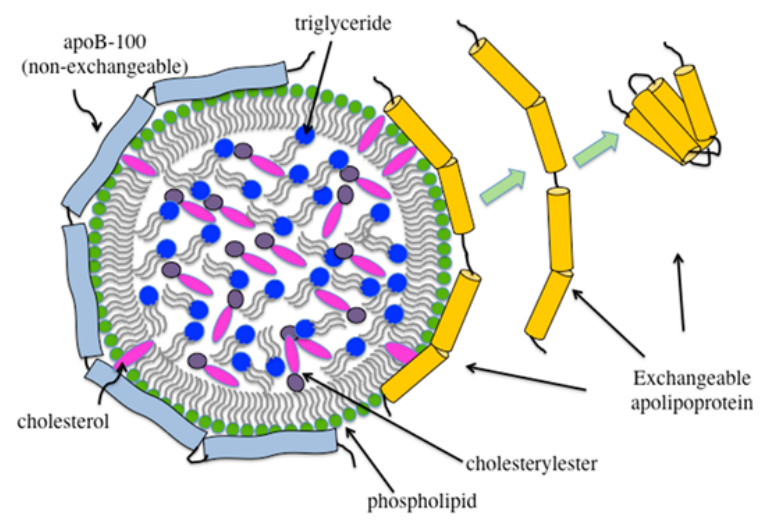

Figure 2. Schematic representation of a generic lipoprotein particle. Lipoproteins have a spherical geometry with a monolayer of amphipathic lipids and proteins encircling a core of neutral lipids. ApoB100 (pale blue) is a single large polypeptide and is the non-exchangeable component of lipoproteins such as VLDL and LDL. The molecular mass of exchangeable lipoproteins (yellow cylinders) varies from 8-50 kDa. The exchangeable apolipoproteins have the ability to exist in lipid-free and lipid-bound states.

The protein composition and content of the lipoproteins also vary significantly from one particle to another. There are two types of apolipoproteins: non-exchangeable and exchangeable. The non-exchangeable apolipoproteins, apolipoprotein B-100 (apoB-100) and apoB-48, are present as a single copy per lipoprotein particle: apoB-100 on VLDL, IDL or LDL and apoB-48 on CM and CM remnants. ApoB-100 is 4536 residues long that is synthesized in the liver, while apoB- 48 , represents the N-terminal $48 \%$ of apoB- 100 , and is synthesized in the intestines. Both apoB-100 and apoB-48 are integral to the structure and stability of the lipoprotein particle. There are different types of exchangeable apolipoproteins, Table 1, which undergo a reversible association with lipoproteins depending on the metabolic state. 


\begin{tabular}{|c|c|c|}
\hline Apolipoprotein & Lipoprotein & Function \\
\hline ApoAI & HDL & $\begin{array}{l}\text { activates LCAT; promotes ABCA1- } \\
\text { mediated cholesterol efflux in RCT }\end{array}$ \\
\hline ApoAII & HDL & Inhibits LCAT \\
\hline ApoAIV & Chylomicrons, HDL & $\begin{array}{l}\text { Activates LCAT, cholesterol clearance } \\
\text { and transport }\end{array}$ \\
\hline ApoB-48 & $\begin{array}{l}\text { Chylomicron and chylomicron } \\
\text { remnants }\end{array}$ & $\begin{array}{l}\text { Cholesterol clearance and transport; } \\
\text { lacks LDLr binding sites }\end{array}$ \\
\hline ApoB-100 & VLDL, IDL and LDL & Binds to LDLr \\
\hline ApoCI & VLDL, HDL & Activates LCAT \\
\hline ApoCII & VLDL, IDL, chylomicrons & Activates lipoprotein lipase \\
\hline ApoCIII & VLDL, IDL, chylomicrons & Inhibits lipoprotein lipase \\
\hline ApoD & HDL & Carrier proteins family (lipocalins) \\
\hline ApoE2 & $\begin{array}{l}\text { VLDL, IDL, chylomicrons, } \\
\text { chylomicron remnants }\end{array}$ & $\begin{array}{l}\text { Poor LDLr binding activity; } \\
\text { associated with Type III } \\
\text { hyperlipoproteinemia and CVD }\end{array}$ \\
\hline ApoE3 & $\begin{array}{l}\text { HDL, VLDL, IDL, chylomicron } \\
\text { remnants (higher binding } \\
\text { preference for HDL over VLDL) }\end{array}$ & $\begin{array}{l}\text { Binds to LDLr family of proteins with } \\
\text { high affinity; significant role in } \\
\text { cholesterol efflux and RCT in } \\
\text { atherosclerosis }\end{array}$ \\
\hline ApoE4 & $\begin{array}{l}\text { VLDL, HDL, IDL, chylomicron } \\
\text { remnants (higher binding } \\
\text { preference for VLDL over HDL) }\end{array}$ & $\begin{array}{l}\text { Binds to LDLr family of proteins with } \\
\text { high affinity; associated with CVD } \\
\text { and Alzheimer's disease }\end{array}$ \\
\hline ApoM & HDL & Transports sphingosine-1-phosphate \\
\hline Apo(a) & Lipoprotein(a) (Lp(a)) & $\begin{array}{l}\text { Linked to apoB-100 via disulfide } \\
\text { bond; similar to plasminogen }\end{array}$ \\
\hline
\end{tabular}

${ }^{1}$ Adapted with permission from the AOCS Lipid Library, "Plasma Lipoproteins: Composition, Structure and Biochemistry," Table 3, "The main properties of apoproteins, in http://lipidlibrary.aocs.org/lipids/lipoprot/index.htm, accessed June 12, 2012

Table 1. Major apolipoprotein components of lipoproteins and associated functions ${ }^{1}$

The exchangeable apolipoproteins have the ability to exist in lipid-free and lipid-bound states, and undergo a large conformational change upon transitioning from one state to the other. Exchangeable apolipoproteins are characterized by an abundance of amphipathic $\alpha$ helices that are folded into a helix bundle. For example, in the case of apoE, the protein is composed of a series of $\alpha$-helices that are folded into an N-terminal (NT) and a C-terminal (CT) domain. The NT domain is comprised of a 4-helix bundle bearing the LDLr binding sites on helix 4, which has an abundance of basic residues, while the CT domain harbors high-affinity lipid binding sites and apoE self-association sites. A similar arrangement was noted for apoAI; however, apoAI does not have the capability to interact with LDLr. 
In summary, lipoprotein particles offer several targets that are vulnerable to attack by oxidative species. Oxidative modification is expected to compromise the structure and function of the protein and lipid components.

\section{Oxidative stress}

Reactive oxygen species (ROS) generally refer to oxygen free radicals with one or more unpaired electrons, and other highly reactive oxygen-containing molecules. They may be generated by the cells as products of normal cellular metabolism, or derived from exogenous sources including environmental pollutants, which could in turn, trigger further release of ROS. Whereas the ROS may be beneficial at low concentrations and play key physiological roles, their deleterious effect at high concentrations contributes to the etiology of several disease states. Organisms have developed an exquisite arsenal of defense mechanisms to combat the harmful effects of ROS, thereby maintaining a redox homeostasis. However, when the ROS overcome the cellular defense mechanism, there is a dysregulation of the redox balance, which leads to the state of oxidative stress (Esterbauer et al., 1991).

\subsection{ROS}

The high reactivity of free radicals is attributed to the unpaired electron(s) on the oxygen molecule. The primary ROS is the superoxide anion, which is generated by the addition of one electron to molecular oxygen during mitochondrial electron transport (Equation 1). This in turn gives rise to hydrogen peroxide following the action of antioxidant enzymes, superoxide dismutases (SOD) (Equation 2). The superoxide anions also give rise to the hydroxyl radicals in the presence of trace amounts of $\mathrm{Fe}^{2+}$ (Fenton reaction) (Equation 3); the hydroxyl radical is an extremely deleterious species that is capable of causing indiscriminate damage in the immediate vicinity of its formation.

$$
\begin{array}{cc}
\mathrm{O}_{2}+\mathrm{e}^{-} \longrightarrow \cdot \mathrm{O}_{2}^{-} & \text {Superoxideanion } \\
\bullet \mathrm{O}_{2}^{-}+2 \mathrm{H}^{+} \stackrel{\mathrm{SOD}}{\longrightarrow} \mathrm{H}_{2} \mathrm{O}_{2}+\mathrm{O}_{2} & \text { Hydrogen peroxide } \\
\bullet \mathrm{O}_{2}^{-}+\mathrm{H}_{2} \mathrm{O}_{2} \stackrel{F e^{2+}}{\longrightarrow} \bullet \mathrm{OH}+\mathrm{OH}^{-}+\mathrm{O}_{2} & \text { Hydroxyl radical }
\end{array}
$$

SOD catalyzes the dismutation of superoxide anion into oxygen and hydrogen peroxide, thereby affording protection to the cell. Three forms of SOD exist in humans and other mammals: SOD1 is located in the cytoplasm, SOD2 in the mitochondria, while SOD3 is extracellular. Mutations in SOD lead to diseases commonly associated with high oxidative stress such as familial amyotrophic lateral sclerosis, Parkinson's Disease, and cardiovascular disease (Fukai et al., 2002; Noor et al., 2002; Tórsdóttir et al., 2006). Overexpression of SOD inhibits LDL oxidation by endothelial cells (Fang et al., 1998). Higher SOD levels were demonstrated to be protective against LDL oxidation in vitro (Laukkanen et al., 2000). 
Red blood cells (RBC) are particularly susceptible to ROS and free radical stress due to its constant interactions with oxygen. Despite their lack of mitochondria, RBC are under tremendous oxidative stress, due to the abundance of hemoglobin. Hemoglobin is prone to oxidation through either exogenous or endogenous sources, which results in superoxide production. Therefore, the RBC contains many SOD enzymes to convert the superoxides to hydrogen peroxide. Furthermore, hydrogen peroxide can combine with hemoglobin to form ferrylhemoglobin, a strong oxidizing agent (Rifkind et al, 2002). The RBCs are also equipped with other antioxidant enzymes such as catalase and glutathione peroxidase to overcome the harmful effects of ROS.

\subsection{Reactive aldehydes}

It is well established that polyunsaturated fatty acids (PUFA) undergo lipid peroxidation that is initiated by ROS, which generate a 'spectrum' of reactive aldehyde species. The reactive aldehydes formed in biological systems are more complex than those formed in simple systems like purified lipid preparations and their physiological concentrations are believed to be lower. They play a crucial role in amplifying the free radical-initiated reaction by generating a complex array of toxic end products. Although considered as end products of oxidative damage of lipids, the aldehydic products display reactivity with a wide variety of biological molecules under cellular conditions, thereby enhancing the pathogenesis of the diseases. They are therefore considered as toxic second messengers of oxidative stress and lipid peroxidation. Protein-bound aldehydes have been proposed as potential markers of oxidative stress as evidenced by immunohistochemical analysis of atherosclerotic lesions (Uchida et al., 1998a). Numerous $\alpha, \beta$-unsaturated aldehydes have been reported in literature: we will focus on acrolein, 4-hydroxynonenal (4-HNE) and malondialdehyde (MDA), Figure 3.

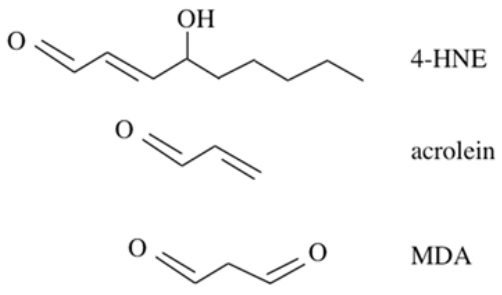

Figure 3. Major aldehydic products of lipid peroxidation

\subsubsection{Acrolein}

Acrolein is an acrid smelling environmental pollutant that is formed during combustion of organic and plastic substances (Beauchamp et al., 1985). It is present as one of the major components in the gaseous phase of tobacco smoke (up to $140 \mu \mathrm{g} /$ cigarette) (Witz, 1989). It is also generated as a natural metabolite during oxidative stress mediated lipid peroxidation 
(Uchida et al., 1998b). In addition, oxidation of threonines by myeloperoxidase (MPO) gives rise to acrolein (Anderson, et al., 1997; Savenkova et al., 1994). Acrolein is the most reactive of all $\alpha, \beta$-unsaturated aldehydes; it causes oxidative modification of proteins by reacting with the sulfhydryls of cysteines, $\varepsilon$-amino groups of lysines and imidazole group of histidines (Witz, 1989; Esterbauer et al., 1991). Some possible products formed upon reaction of acrolein with lysine side chains include aldimine adducts (Schiff base formation), propanal adducts (Michel addition) and $\mathrm{N}^{\varepsilon}$-(3-formyl-3,4-dehydropiperidino)lysine (FDPlysine), Figure 4.

\subsubsection{4-HNE}

Discovered more than 50 years ago, alkenals have been under intense scrutiny in terms of their chemistry, biochemistry, toxicology and as oxidative stress agents. Amongst these alkenals, 4-HNE was determined to be the most toxic. It was discovered to be a product of lipid peroxidation, particularly of n-6 PUFA such as linoleic acid and arachidonic acid. Since then, 4-HNE has been implicated in a number of diseases, including atherosclerosis, Alzheimer's Disease, Parkinson's Disease, liver cirrhosis, and cancer (Zarkovic, 2003).

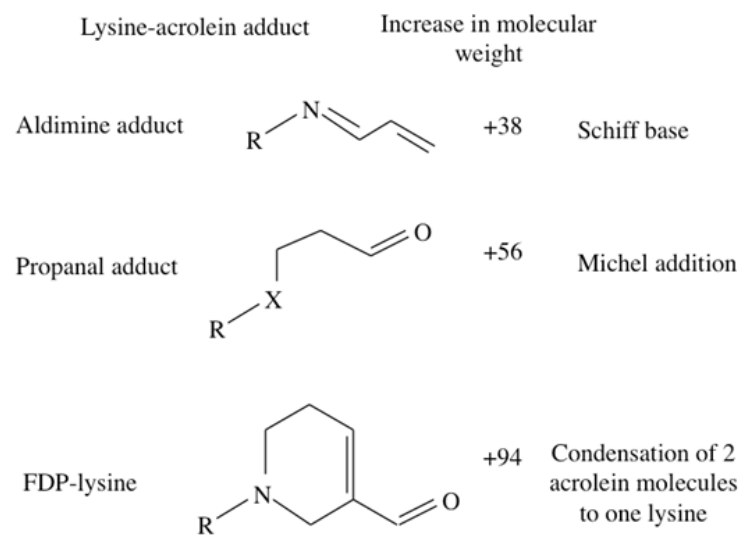

Figure 4. Modifications of lysine side chains by acrolein. The major lysine modification products of acrolein are shown, along with the expected increments in molecular weight during mass spectral analysis. Adapted from Furuhata et al, 2003.

From a chemical perspective, the reactivity of 4-HNE is conferred by the carbonyl group at $\mathrm{C} 1$ position, and a $\mathrm{C}=\mathrm{C}$ bond between the second and third carbons which provide a partial positive charge to C3 (Schaur, 2003). This results in 4-HNE being highly reactive towards thiol and amino groups of proteins. 4-HNE reacts with thiols via a Michael addition, in which a nucleophile such as the sulfhydryl of cysteine or glutathione reacts with the C3 of HNE to form a covalent adduct. In addition, amino compounds such as lysine, ethanolamine, guanine, and the imidazole group of histidine are capable of forming Michael addition adducts with 4-HNE. 4-HNE can also undergo reactions involving a reduction or an epoxidation of the double bond. 4-HNE has been shown to react in vivo with common 
biomolecules, and can often have an inhibitory role with enzymes (Schaur, 2003; Korotchkina et al, 2001). Cross-reactivity of anti-4-HNE antibody with oxidized LDL (OxLDL) suggests that 4-HNE may contribute to the overall process of atherosclerotic plaque formation (Uchida et al., 1993).

\subsection{3. $M D A$}

In fresh samples, MDA is formed mainly from PUFA such as arachidonic acid (Esterbauer et al., 1991). Initially determined by the thiobarbituric acid (TBA) assay as TBA reactive substances (TBARS), the presence of pre-existing MDA or protein-bound MDA needs to be confirmed by other sensitive assays as well. Under physiological conditions, MDA readily modifies protein side chains forming stable cross-linked adducts with the $\varepsilon$-amino groups of lysines. Other side chains that may be modified include those of histidine, tyrosine, arginine and methionine.

While the levels of acrolein, 4-HNE, MDA and other aldehydic compounds per se are thought to be too low for detection, their role in mediating oxidative damage has been confirmed by the presence of autoantibodies against aldehyde-modified proteins. It provides evidence for the in vivo occurrence of lipid peroxidation products and their role in disease progression (Steinberg et al, 1989). We have a better understanding of the association between lipid peroxidative products, oxidative stress and disease progression, in part due to the development of antibodies directed against oxidized lipids and protein-bound aldehydes in the past two decades, Table 2. Currently, we have a repertoire of antibodies directed against different types of oxidatively modified lipids and proteins, Table 2, that serve as powerful tools for ELISA, immunohistochemical and immunoblotting analyses.

\subsection{Sources of ROS}

In addition to the mitochondrial electron transport, there are enzymatic sources of ROS that contribute to the redox status in biological systems. Located in the blood stream, they are of relevance to lipoprotein oxidation.

\subsection{1. $M P O$}

MPO is an enzyme found abundantly in neutrophil granulocytes and to some extent in macrophages. It is a lysosomal protein stored in the azurophilic granules in neutrophils and can be identified by its characteristic green heme pigment. During the respiratory burst of the neutrophil, MPO catalyses the production of hypochlorous acid $(\mathrm{HOCl})$ from hydrogen peroxide and chloride anion (Equation 4). MPO is also responsible for generation of 3chlorotyrosine and 3-nitrotyrosine; individuals with coronary artery disease show elevated levels of these two products in their blood and HDL. MPO has been shown to play a role in promoting atherosclerotic lesions through oxidative modification of apoAI (Shao et al., 2012) (described under apoAI).

$$
\mathrm{H}_{2} \mathrm{O}_{2}+\mathrm{Cl}^{-}+\mathrm{H}^{+} \rightarrow \mathrm{HOCl}+\mathrm{H}_{2} \mathrm{O}
$$




\begin{tabular}{|c|c|c|}
\hline Lipid peroxidation products & $\mathrm{mAb}$ & Epitope \\
\hline \multicolumn{3}{|l|}{ Oxidized lipids } \\
\hline a9-Hydroxy-10E,12Z-octadecadienoic acid (9-HODE) & $9 \mathrm{H} 2$ & 9-HODE \\
\hline b13-Hydroxy-9Z,11E-octadecadienoic acid (13-HODE) & $13 \mathrm{H} 1$ & 13-HODE \\
\hline a12-Hydroxyeicosatetraenoic aci (12-HETE) & $12 \mathrm{H} 8$ & 12-HETE \\
\hline aLeukotoxin (epoxylinoleic acid) & 21D1 & Leukotoxin \\
\hline a7-Ketocholesterol (7-KC) & $35 \mathrm{~A}-8$ & $7-\mathrm{KC}$ \\
\hline c15-deoxy- $\Delta^{12,14}$-prostaglandin $\mathrm{J}_{2}\left(15 \mathrm{~d}-\mathrm{PG} \mathrm{J}_{2}\right)$ & $11 \mathrm{G} 2$ & $15 \mathrm{~d}-\mathrm{PGJ} 2$ \\
\hline \multicolumn{3}{|l|}{ Protein-bound aldehydes } \\
\hline dAcrolein (ACR) & $5 \mathrm{~F} 6$ & ACR-lysine \\
\hline${ }^{\mathrm{e} C}$ rotonaldehyde (CRA) & 82D3 & CRA-lysine \\
\hline a2-Hexenal (HE) & CT5 & HE-lysine \\
\hline f2-Nonenal (NE) & 27Q4 & NE-lysine \\
\hline gMalondialdehyde (MDA) & $1 F 83$ & MDA-lysine \\
\hline h4-Hydroxy-2-hexenal (HHE) & 53 & HHE-histidine \\
\hline i2-Hydroxyheptanal $(2 \mathrm{HH})$ & $3 C 8$ & 2-HH-lysine \\
\hline ¡4-Hydroxy-2-nonenal (HNE) & HNEJ2 & HNE-histidine \\
\hline k4-Hydroxy-2-nonenal (HNE) & 2C12 & HNE-lysine \\
\hline '4R-4-Hydroxy-2-nonenal ((R)-HNE) & R310 & (R)-HNE-histidine \\
\hline m4S-4-Hydroxy-2-nonenal ((S)-HNE) & S412 & (S)-HNE-histidine \\
\hline n4-Hydroperoxy-2-nonenal (HPNE) & PM9 & HPNE-lysine \\
\hline ○4-Oxo-2-nonenal (ONE) & $9 \mathrm{~K} 3$ & ONE-lysine \\
\hline \multicolumn{3}{|l|}{ Protein-bound core aldehyde } \\
\hline p9-Oxononanoylcholesterol (9-ONC) & $2 \mathrm{~A} 81$ & 9-ONC-lysine \\
\hline
\end{tabular}

anpublished

bShibata et al. (2009) Acta Histochem. Cytochem. 42, 197; cShibata et al. (2011) JBC 277, 10459; dUchida et al. (1998) PNAS 95, 4882; eIchihashi et al. (2002) JBC 276, 23903; Ishino et al. (2010) JBC 285, 15302; gYamada et al. (2001) JLR 42, 1187; hYamada et al. (2004) JLR 45, 626; iItakura et al. (2003) BBRC 308, 452; iToyokuni et al. (1995) FEBS Lett. 359, 189;

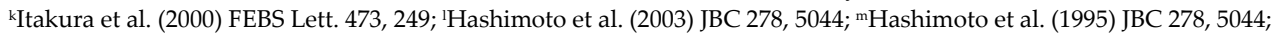
"Shimozu et al. (2011) JBC 286, 29313; 'Shibata et al. (2011) JBC 286, 19943; pKawai et al. (2003) JBC 278, 21040; qKawai et al. (2003) JBC 278, 50346

Table 2. Lipid peroxidation-specific monoclonal antibodies

\subsubsection{NADPH oxidase}

NADPH oxidase is an enzyme complex that is normally found in the plasma membranes of neutrophils and monocytes. Like MPO, it is activated during the respiratory burst of the neutrophil. Its main role is to generate superoxide by transferring electrons from NADPH to molecular oxygen (Equation 5). The superoxide is then used to destroy phagocytosed bacteria or pathogens. NADPH oxidase and its product, superoxide, are major contributory factors for foam cell formation in atherosclerosis (Meyer \& Schmitt, 2000). 


$$
2 \mathrm{O}_{2}+\mathrm{NADPH} \rightarrow 2 \bullet \mathrm{O}_{2}^{-}+\mathrm{NADP}^{+}+\mathrm{H}^{+}
$$

\subsubsection{Lipoxygenase}

Lipoxygenases are iron-containing enzymes that catalyze the dioxygenation of PUFA in lipids. Specifically, they form hydroperoxides from fatty acids and molecular oxygen. 15lipoxygenase is the main protein in this family; it is involved in the metabolism of eicosanoids (prostaglandins, leukotrienes), which function as secondary messengers. 15lipoxygenase has been shown to be involved in LDL oxidation (Bailey et al., 1995), with considerably greater 15-lipoxygenase activities in atherosclerotic compared to normal aortas (Hiltunen et al., 1995).

\section{Lipoprotein oxidation}

We now turn to the specifics of lipoprotein oxidation with reference to the different lipid and protein components.

\subsection{Oxidation of lipid components}

Of the different lipid components that may be potentially oxidized in various lipoprotein particles, we will focus on the oxidation of fatty acyl chains, including those on phospholipids, cholesterylester and triglycerides, and on cholesterol derivatives. The reader is referred to a comprehensive review by Subbaiah and colleagues (Levitan et al., 2010) for an introduction to the role of ceramides in Ox-LDL and of sphingosine 1-phosphate in HDL

\subsubsection{Oxidation of fatty acyl chain}

One group of biological targets that are highly vulnerable to attack by ROS and aldehydes are the lipids: their abundance in lipoproteins and the ease with which their unsaturated bonds are oxidatively modified make them susceptible to damage. Products of lipid peroxidation have been associated with the pathophysiology of numerous disease states, including atherosclerosis, diabetes and cancer. Although found in low concentrations in normal healthy tissues, they are found to be enriched in pathological cells and tissues, including macrophage foam cells and atherosclerotic lesions (Olkkonnen, 2008; Brown \& Jessup, 1999; Olkkonen \& Lehto, 2004; Javitt, 2008; Tsimikas et al., 2005; Berliner \& Watson, 2005). PUFA peroxidation products cause further damage to proteins by oxidative modification of amino acid side chains and formation of protein carbonyl groups (Refsgaard et al., 2000).

Briefly, lipid peroxidation is initiated by the hydroxyl radical abstracting a hydrogen from the methylene group adjacent to a double bond of fatty acids, Figure 5. The fatty acid may also be part of the phospholipid at the $s n-2$ position or esterified to the $-\mathrm{OH}$ group of cholesterol in a lipoprotein. This process gives rise to an unstable lipid radical, which undergoes rearrangement of double bonds and addition of oxygen to form a peroxyl radical. 
The lipid radical or the peroxyl radical could react with a neighbouring fatty acyl chain as well, thereby propagating the peroxidation process. The chain reaction may be terminated by eventual formation of a lipid hydroperoxide.

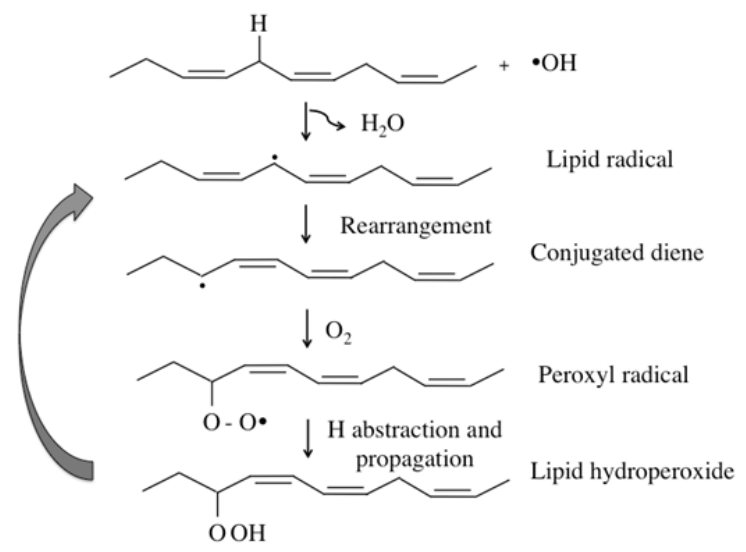

Figure 5. Lipid peroxidation. The lipid peroxidation process may be divided into the initiation, propagation and termination steps; only the double bond containing segment of a fatty acid is shown.

In the context of a lipoprotein, it was postulated that LDL oxidation was initiated through cellgenerated ROS formation, with the involvement of the lipoxygenase pathway (Cyrus et al, 1999). Both apoE-null and LDLr-null mice genetically deficient in the 12/15-lipoxygenase were found to have significantly less atherosclerosis. Other groups developed mice overexpressing the 12/15-lipoxygenase, and found spontaneous aortic fatty streak lesions on a chow diet (Reilly et al., 2004). Finally, it was shown that the endothelial cells within the vessels required 12/15-lipoxygenase to generate oxidized phospholipids. It was also shown that the MPO pathway contributed to Ox-LDL in human atherosclerotic lesions (Savenkova et al., 1994).

LDL oxidation may occur within the arterial endothelial cells, which have high levels of precursor molecules like linoleic acid and arachidonic acid - fatty acids that are involved in producing eicosanoids. Hydroperoxide reaction with linoleic acid produces 13(S)hydroperoxy-octadecadienoic acid (13(S)-HPODE), and reaction with arachidonic acid produces 15(S)-hydroperoxy-eicosatetraenoic acid (15(S)-HPETE). These molecules are present as part of LDL surface phospholipids and trigger further oxidation of phospholipids with arachidonic acid. These are early events occurring prior to apoB-100 modification and constitute the 'minimally-modified' LDL (Navab et al., 2001). Another consequence of phospholipid oxidation is fragmentation of the fatty acyl group at $s n-2$ position resulting in short chain fatty acids, which structurally and functionally resemble platelet activating factors with chemotactic activity.

Although less understood, in vitro oxidation of HDL is also shown to generate oxidized lipids and proteins. It is likely that HDL lipids may be oxidized initially even before LDL lipids, upon exposure of human plasma to peroxyl radicals, $\mathrm{Cu}^{2+}$ ions or lipoxygenase 
(Garner et al., 1998). These studies also show that Met residues are oxidized in apoAI and apoAII. Further, ${ }^{1} \mathrm{H}$ and ${ }^{31} \mathrm{P}$ NMR analysis indicate a loss of the unsaturated system with appearance of epoxides on fatty acyl chains and 5,6-epoxide derivatives of cholesterol indicating significant modification of HDL (Bradamante et al., 1992).

\subsubsection{Oxysterols}

Oxysterols are molecules that are formed from the oxidation of cholesterol, which can occur at several sites (Vaya \& Schipper, 2007). They display higher water solubility compared to cholesterol. The major oxysterols isolated from plasma LDL include $7 \alpha-\mathrm{OH}$ and $7 \beta-\mathrm{OH}$ cholesterol. In addition, 7-keto cholesterol, which impairs cholesterol efflux and reduces cell membrane fluidity, and 5,6-epoxide derivatives of cholesterol, have also been identified in Ox-LDL (Levitan et al., 2010). Other types of oxysterols have been localized in atherosclerotic lesions, including those wherein the side chains of cholesterol are oxidized (for example, 27-hydroxycholesterol). The cytochrome P-450 system is largely responsible for generating the hydroxylated derivatives. They also function as transcriptional effectors and attenuate the Liver X Receptor (LXR). A majority of PUFA in LDL is esterified as cholesterylester; thus, hydroperoxide and hydroxide derivatives of cholesterylester are found in abundance in human atherosclerotic lesions.

In the CNS, the neurons convert cholesterol to 24S-hydroxycholesterol (also known as cerebrosterol), Figure 6; the conversion facilitates its movement out of the CNS, since cholesterol as such does not cross the blood brain barrier. Almost all circulating 24Shydroxycholesterol originates from the brain (Lutjohann et al., 1996; Lutjohann et al., 2000; Bjorkhem et al., 1998) and may reflect CNS cholesterol turnover.

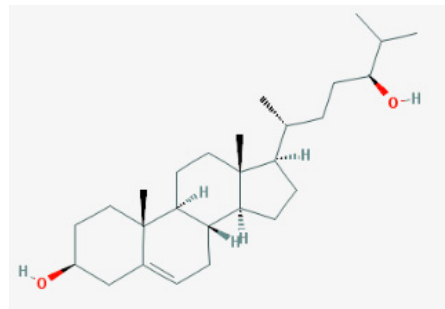

Figure 6. 24S-hydroxycholesterol (obtained from: http://pubchem.ncbi.nlm.nih.gov)

\subsection{Oxidation of protein components}

\subsection{1. $A$ poB-100}

From a historical perspective, apoB-100 was the earliest apolipoprotein to be identified as being a target for oxidative modification on lipoproteins (Steinberg et al., 1989). It is implied in the discussions involving Ox-LDL hypothesis, along with oxidation of the lipid moieties in LDL. The term Ox-LDL is used to identify LDL that has been modified to an extent that it is not recognized by the LDLr anymore; instead it becomes a ligand for the scavenger 
receptors family of proteins. On the other hand, the term 'minimally-modified' LDL has been adopted to encompass the different preparations that have been modified enough to be chemically distinguishable from, but recapitulates the LDLr binding feature of, unmodified LDL. ApoB-100 is one of the oxidizable targets on lipoproteins: one of the earliest in vitro studies demonstrate that incubation of human LDL with 4-HNE (Haberland et al., 1984; Jurgens et al., 1986), results in modification of 45 lysines, 7 histidines, 23 serines and 51 tyrosine residues on apoB-100.

4-HNE forms covalent adducts with lysine residues on apoB-100, thereby blocking its ability to recognize the macrophage LDLr. Evidence for in vivo LDL oxidation was provided by immunocytochemical staining and immunoblot analysis of extracts from atherosclerotic lesions of LDLr-deficient rabbits using antibodies against Ox-LDL, MDA-lysine or 4-HNElysine, (Palinski et al., 1990). This study also demonstrated higher titers of autoantibodies against MDA-conjugated LDL in the human and rabbit antisera. 4-HNE-modified LDL is an efficient ligand for scavenger receptors (Hoff \& O'Neil, et al, 1993; Rosenfeld et al., 1990). ApoB-100 can also be modified by MPO, which leads to formation of chlorotyrosine and nitrotyrosine derivatives.

\subsubsection{ApoE}

ApoE is a 299 residue, $34 \mathrm{kDa}$ protein that is commonly associated with VLDL, CM remnants and a sub-class of HDL. It is a major cholesterol transport protein in the plasma and the CNS (Hatters et al., 2006). In humans, apoE is polymorphic; variation in the APOE gene results in three major alleles, $\varepsilon 2, \varepsilon 3$ and $\varepsilon 4$, occurring at frequencies of $8 \%, 77 \%$ and $15 \%$, respectively in the population. The products of the three alleles are the isoforms, apoE2, apoE3 and apoE4, which differ in the amino acids at positions 112 and 158: apoE2 has Cys while apoE4 has Arg at these locations; apoE3 has a Cys and Arg at these locations, respectively. ApoE3 is considered an anti-atherogenic protein; individuals homozygous for the $A P O E \varepsilon 2$ allele are prone to developing familial type III hyperlipoproteinemia and premature atherosclerosis. The inheritance of one or more of the APOE \&4 alleles predisposes the bearer to hypercholesterolemia, as well as Alzheimer's disease, affecting both the age of onset and the severity of these diseases.

In vitro oxidative modification of the receptor-binding domain of apoE3 by acrolein generates epitopes recognized by an antibody specific for acrolein-lysine adducts, mAb5F6 (TamamizuKato et al., 2007) with formation of both intra- and inter-molecular cross-linked products. This modification resulted in severe impairment of three major functions of apoE3: (i) its ability to interact with the LDLr, a function mediated by specific lysines and arginines located on helix 4 of the receptor-binding domain; (ii) its ability to bind heparin, which is facilitated predominantly by two specific lysines (K143 and K146), Figure 7; (iii) its ability to bind lipids. These studies indicate that acrolein either directly modifies the lysines in helix 4 that are involved in LDLr and heparin binding or that modification of lysines elsewhere on apoE3 alters the conformation of lysines in helix 4, thereby disrupting its binding. Further evidence was provided by direct exposure of VLDL isolated from human plasma to acrolein or $\mathrm{Cu}^{2+}$, 
which disrupted its ability to bind and internalize the lipoprotein particle via LDLr, LDLrrelated protein or HSPG on hepatocytes. (Arai et al., 1999; 2005). Taken together, oxidative modification appears to compromise the functional integrity of apoE3.
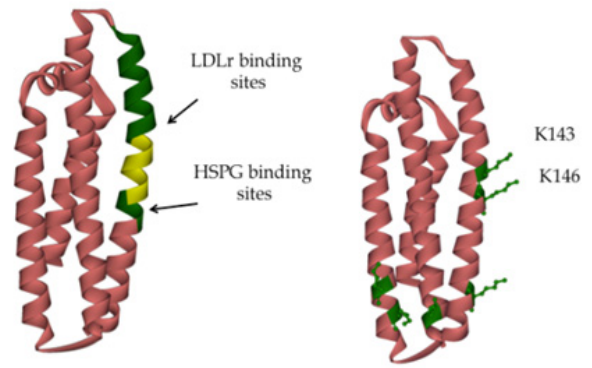

Figure 7. Lysines relevant in LDLr and HSPG binding function of apoE3. Ribbon diagram of apoE3 receptor-binding domain is shown with the LDLr- and HSPG-binding sites represented in green and yellow, respectively.

From a physiological perspective, the loss of apoE function by oxidative modification has direct implications in CVD: (i) decreased uptake and internalization of apoE-containing lipoproteins leading to their accumulation in the blood; (ii) decreased ability of apoE to interact with heparan sulfate proteoglycans (HSPG) lining the blood vessels and cell surfaces, where apoE is believed to be stored; and (iii) impaired ability of apoE to interact with lipoproteins, which is an essential prerequisite for the receptor-binding domain to elicit LDLr binding.

In the CNS, where apoE is the predominant apolipoprotein that has been identified so far, oxidative modification is expected to have serious implications in progression of neurological diseases such as Alzheimer's disease in an isoform-specific manner. About 65\% of individuals with late-onset familial and sporadic Alzheimer's disease bear the APOE $\varepsilon 4$ allele (Huang et al., 2004). The precise mechanism by which apoE4 is associated with Alzheimer's disease remains a contentious issue. While the role of apoE4 in aggravating the beta amyloid toxicity has received widespread attention, the inherent propensity of apoE4 to misfold noted under in vitro physiological conditions requires further scrutiny in vivo. Further, since oxidative damage plays a significant role in the pathogenesis associated with Alzheimer's disease (Perry et al., 2002), it is likely that oxidative modification of apoE4 further exacerbates its role in the etiology of the disease. Indeed, cerebrospinal fluid obtained by lumbar puncture in a limited number of Alzheimer's disease patients homozygous for APOE3 or APOE4, and age-matched controls with or without dementia display a $50 \mathrm{kDa}$ apoE-immunoreactive protein co-migrating with proteins immunoreactive for 4-HNE and MDA adducts (Montine et al., 1996; Bassett et al., 1999).

A similar $50 \mathrm{kDa}$ apoE-immunoreactive protein was also reported in P19 neuroglial cultures differentiated into neurons and astrocytes subjected to oxidative stress. Interestingly, apoE3 appeared to be cross-linked to a greater extent than apoE4. The cross-linking has been attributed to the susceptible site provided by apoE3 in the form of Cys112, and the known reactivity of 4-HNE with sulfhydryl groups (Esterbauer et al., 1991). In vitro modification of 
apoE3 or apoE4 (isolated from plasma) by 4-HNE yielded cross-linked products with apparent molecular weights corresponding to dimeric and trimeric apoE (Montine et al., 1996). A similar trend was noted with MDA. It is possible that the greater susceptibility of apoE3 to crosslinking and oxidation than apoE4 is a reflection of its greater potency as an antioxidant.

\subsubsection{ApoAI}

ApoAI is a 243 residue, $28 \mathrm{kDa}$ exchangeable apolipoprotein that is a major component of HDL. Like apoE, it is composed predominantly of amphipathic $\alpha$-helices, with an Nterminal domain 4-helix bundle. Under normal physiological conditions, apoAI plays a critical role in promoting ATP Binding Cassette Transporter A1 (ABCA1)-mediated cholesterol efflux from macrophages. This aids in mobilizing cholesterol and phospholipids from peripheral tissues to the liver by the RCT process, for eventual disposal by biliary secretion. In atherosclerotic lesions, apoE plays a dominant role in RCT by virtue of the fact that cholesterol-laden macrophages secrete lipid-poor apoE, which in turn in promotes ABCA1-mediated cholesterol efflux (Huang et al, 1995).

With both apoAI and apoE, a nascent discoidal form of HDL is generated that is composed of a bilayer of phospholipids and cholesterol circumscribed by the $\alpha$-helices of the protein. The discoidal HDL is an excellent substrate for LCAT, the enzyme that catalyzes the transfer of a fatty acyl chain from phospholipids to the free hydroxyl group of cholesterol to form cholesterylesters. The conversion of the amphipathic free cholesterol to the hydrophobic cholesterylesters promotes its transition to the core of the lipoprotein particle, thereby generating a spherical HDL containing a cholesterylester core. The HDL is targeted to the liver and steroidogenic tissues where they are recognized by the scavenger receptor class $B$ Type 1 (SR-B1), which mediate selective uptake of cholesterylesters into the cells.
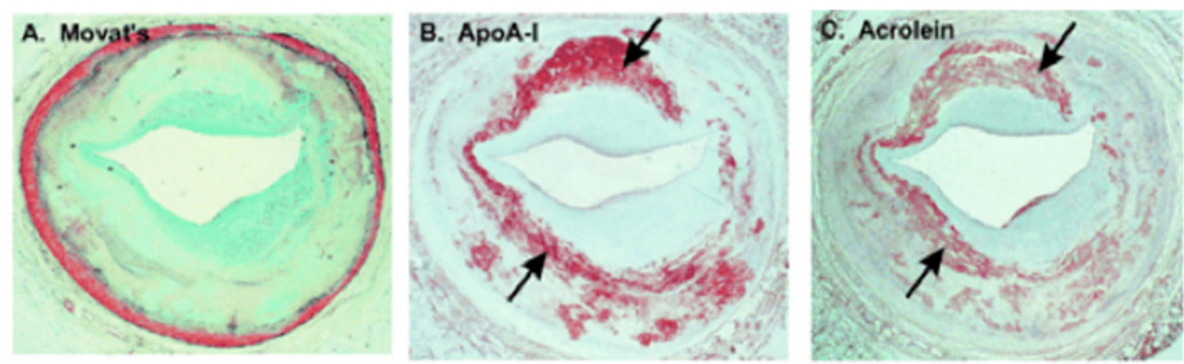

Figure 8. Immunohistochemical co-localization of apoAI and acrolein adducts in human atherosclerotic lesions. This research was originally published in The Journal of Biological Chemistry. Shao, B., Fu, X., McDonald, T. O., Green, P. S., Uchida, K., O’Brien, K. D., Oram, J. F. \& Heinecke, J. W. Acrolein impairs ATP Binding Cassette Transporter A1-dependent cholesterol export from cells through site-specific modification of apolipoprotein A-I. J. Biol. Chem. (2005) Vol. 280, No. 43, pp. 36386-36396 @ the American Society for Biochemistry and Molecular Biology.

There is strong evidence that MPO oxidizes HDL in vivo (Daugherty et al., 1994; Bergt et al., 2004; Pennathur et al., 2004; Zheng et al., 2004). In addition, aldehyde modification of HDL 
is also associated with the loss in ability of HDL to activate LCAT (McCall et al., 1995). Acrolein modifies apoAI specifically at Lys226 in helix 10 converting it to $\mathrm{N}^{\varepsilon}$ (3methylpyridinium)lysine (MP-Lys). A corresponding decrease in ABCA1-mediated cholesterol efflux was also noted. In addition, immunohistochemical analysis demonstrated co-localization of acrolein-adducts and apoAI in human atherosclerotic lesions, Figure 8, confirming previous studies (Uchida et al., 1998b). Further chlorination of Tyr192 and oxidation of specific Met residues in apoAI via the MPO pathway impairs its ability to promote cholesterol efflux (Shao et al., 2010). Taken together, it appears that oxidative modification of HDL apoAI may be one of the contributory factors to atherogenesis.

Figure 9 provides a simplified overview of the roles of apoB-100, apoAI and apoE in lipid distribution between liver and peripheral tissues. It also shows potential functional sites that are likely to be affected because of oxidative modification of lipoproteins.

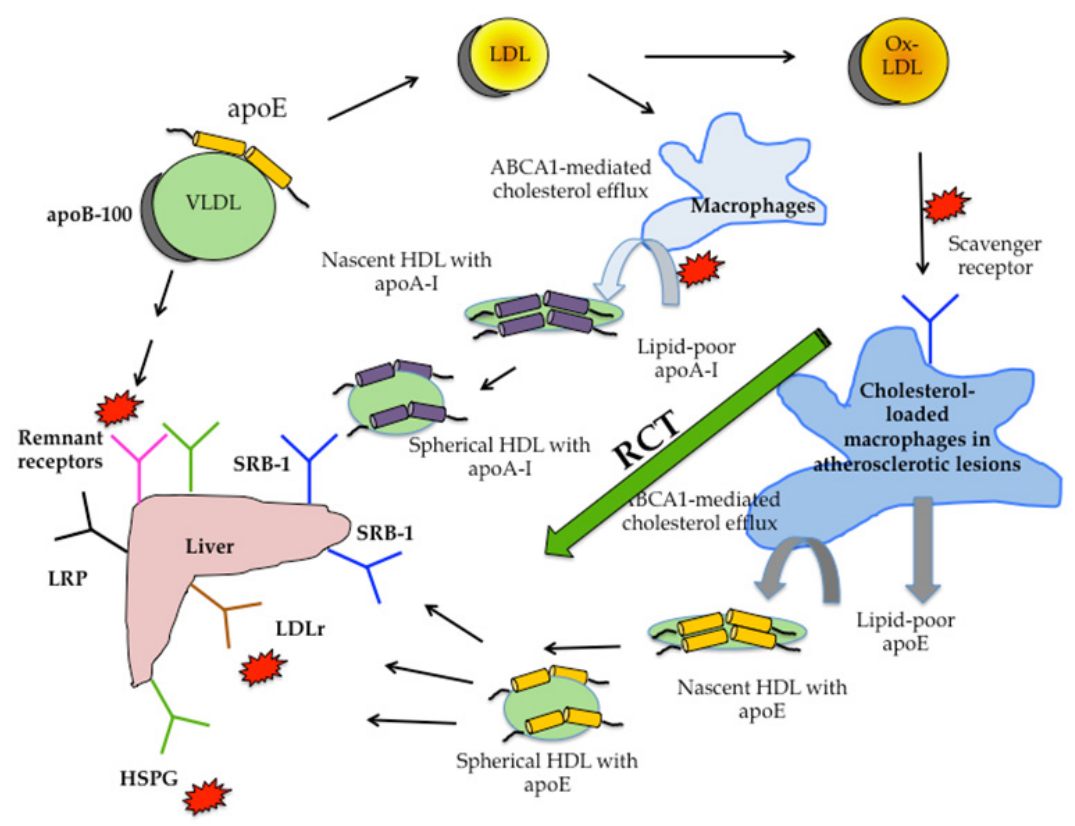

Figure 9. Distribution cholesterol mediated by apoB-100, apoE and apoAI. The green block arrow shows the general direction of the RCT process. The red stars draw attention to processes that are affected by oxidative modification of protein and lipid components of lipoproteins.

\section{Lipoprotein oxidation and disease states}

\subsection{Atherosclerosis}

Atherosclerosis is one of the leading causes of death worldwide, and is commonly associated with coronary and cerebrovascular diseases (Rocha \& Libby, 2009; Moore \& Tabas, 2011). Originally considered purely a lipid-storage disease, it is now recognized that 
atherosclerosis is intrinsically linked to inflammation, particularly with respect to involvement of innate and adaptive immunity.

Atherosclerosis is a progressive disorder marked by several stages with varying extent of lesions marking each stage. It is initiated by accumulation of lipoproteins in the subendothelium, typically at arterial branch points, which tend to have impaired laminar flow. The physiological response to this retention includes: (i) chemical modification (due to the production of ROS and other oxidative factors from intimal macrophages) and aggregation of the lipoproteins, (ii) early inflammatory response such as T cell recruitment, (iii) cytokine secretion, and, (iv) endothelial alterations. In response to the chemokines, the circulating monocytes enter the arterial wall and eventually differentiate to macrophages under the influence of macrophage colony stimulating factors.

The macrophages internalize oxidized and modified lipoproteins via several types of scavenger receptors, including class A and B scavenger receptors (e.g. CD36) and lectin-like oxidized LDLr-1 (LOX-1). Mice lacking CD36, platelet-activating-factor receptor, and tolllike receptors 2 and 4 show decreased atherosclerosis. The internalized cholesterol is stored in the cytoplasm as cholesterylester lipid droplets, surrounded by a monolayer of phospholipids. When viewed by electron microscopy, these cells have a foamy appearance, and are therefore called foam cells. Foam cell formation marks the earliest pathological lesion in atherosclerosis called 'fatty streaks'.

As the fatty streaks progress, they induce migration of smooth muscle cells from media to the intima of the arterial wall, which is accompanied by secretion of collagen and matrix proteins and macrophage proliferation. As lipid accumulation continues to occur in macrophages, smooth muscle cells also take up lipids. Collectively, these processes give rise to fibrous lesions. As the lesion progresses, foam cells die and release lipids, which aggregate with lipoproteins trapped in the matrix, eventually leading to advanced lesions with calcification and hemorrhage.

Ox-LDL also plays a role in modulating smooth muscle function, by increasing their adhesion to macrophages and foam cells in the plaques. At low concentrations, Ox-LDL stimulates proliferation of smooth muscle cells, whereas at higher concentrations, they cause smooth muscle apoptosis by up-regulating levels of the pro-apoptotic lipid ceramide. During this process, a necrotic core is formed in the vessel lumen. The necrotic plaque is unstable and subject to disintegration or rupture, leading to formation of a thrombus. OxLDL are key stimulators of the coagulation pathway, and promote the secretion of tissue factor from endothelial cells, which is required to form a clot. At various stages of the lesions unstable angina, heart attack or stroke may occur.

In summary, our understanding of the atherogenesis process has progressed rapidly since the deleterious nature of Ox-LDL was first pointed out about 3 decades back. We now recognize it as a multifactorial disease with inflammation and oxidative stress playing key roles. The last decade has seen the additional role of HDL in mitigating the severity of atherosclerosis; in this context, the role of HDL (not HDL levels per se, but the robustness of HDL function) is currently under intense scrutiny. 


\subsection{Alzheimer's disease}

Alzheimer's disease is a neurodegenerative disorder that is clinically characterized by progressive cognitive decline and dementia. The major neuropathological hallmarks of this age-related disease are the extra cellular accumulation of amyloid beta peptide $(\mathrm{A} \beta)$, the intracellular presence of neurofibrillary tangles composed of hyperphosphorylated tau and the loss of cholinergic neurons in the brain.

Several hypotheses have been put forward to explain the pathogenesis of Alzheimer's disease, of which the oxidative stress hypothesis is of relevance here. In general, the brain of Alzheimer's disease subjects is believed to be in a heightened state of oxidative stress and is characterized by higher levels of lipid peroxidation products (acrolein, 4-HNE and MDA) (Arlt et al., 2002; Butterfield et al., 2010). The brain is particularly susceptible to oxidative stress due to the high oxygen and metal content, lipid levels, and paucity of antioxidants (such as vitamins C and E) compared to normal tissues (Schippling et al., 2000). The Alzheimer's disease brain is also rich in isoprostanes (a stable marker of peroxidation of arachidonic acid) and neuroprostanes (Lovell et al., 2001).

Accumulation of soluble and insoluble assemblies of $\mathrm{A} \beta$ (a peptide composed of 39-43 residues) in the brain parenchyma and in the cerebral vasculature is considered the primary event in Alzheimer's disease pathogenesis by the amyloid hypothesis. A $\beta$ is derived from the ubiquitously expressed transmembrane protein amyloid precursor protein by regulated intramembranous proteolysis. The oligomeric form of $\mathrm{A} \beta$ is considered as the most toxic species; one of the reasons for its toxicity is its ability to act as an oxidative stress agent in a lipid environment. The oxidative nature of $A \beta$ has been attributed to the presence of Met35, which is capable of undergoing one-electron oxidation to form a sulfuranyl radical cation $(\mathrm{S} \bullet+)$. This in turn is able to abstract a $\mathrm{H}$-atom from a fatty acyl chain as shown in Figure 7, and initiate a series of free radical-mediated events in a lipid milieu such as a membrane bilayer or a lipoprotein particle (Butterfield et al., 2005).

In the CNS, apoE is localized on HDL-sized spherical and discoidal particles. Lipoproteins isolated from CSF of Alzheimer's disease patients were shown to have a higher sensitivity to in vitro oxidation compared to those from normal subjects. It has also been shown that CSF lipoproteins can be oxidized through transition metal ions such as $\mathrm{Cu}^{2+} \mathrm{or} \mathrm{Fe}^{3+}$. These metal ions are present in CSF as complexes with metal-binding proteins like ceruloplasmin or transferrin (Schippling et al., 2000); under pathological conditions, they are released in a catalytically active form. Furthermore, A $\beta$ itself can induce oxidation through interactions with metal ions. $A \beta$ contains three histidines and one tyrosine, all of which can chelate transition metal ions. This promotes $A \beta$ aggregation and a pro-oxidative state of $A \beta$ through reduction of the transition metal (Artl, et al., 2002). The peptide can then produce ROS or induce lipid peroxidation, both of which strongly affect lipoprotein stability.

Conversion of cholesterol to 24S-hydroxycholesterol is believed to be a mechanism by which the brain maintains cholesterol homeostasis. Plasma concentrations of 24S- 
hydroxycholesterol are utilized as a biomarker and a diagnostic tool for neurological disorders. Neuronal damage is accompanied by destruction of neuronal membranes, which causes more cholesterol to be converted into 24S-hydroxycholesterol. In agreement significantly higher peripheral concentrations of 24S-hydroxycholesterol were found in Alzheimer's disease and vascular demented patients (Lutjohann at al., 2000). Importantly, the latter study showed that the apoE genotype does not contribute significantly to the elevated plasma levels of 24S-hydroxycholesterol in Alzheimer's disease patients (Bretillon, 2000).

The CSF levels of 24S-hydroxycholesterol appears to be sensitive to changes in the brain (possibly because they are not affected by hepatic clearance rates of this oxysterol) and may represent better markers both for neurodegenerative diseases and for disturbances in the blood brain barrier (Leoni \& Caccia, 2011). In early stages of Alzheimer's disease, there are significantly higher CSF concentrations of 24S-hydroxycholesterol suggesting increased cholesterol turnover in the CNS during degeneration (Leoni \& Caccia, 2011). These levels decrease as the disease advances, possibly reflecting the loss of cells expressing cholesterol 24S-hydroxylase, the enzyme responsible for the conversion of brain cholesterol into 24Shydroxycholesterol. In Alzheimer's disease and mild cognitive impairment, but not in normal individuals, the levels of 24S-hydroxycholesterol significantly correlate with CSF levels of apoE (Shafaati et al., 2007).

The elevation of 24S-hydroxycholesterol in CSF is consistent with a significant role for this oxysterol as a signaling molecule during neuronal degeneration. It has been shown that 24Shydroxycholesterol is able to induce expression of apoE and $A B C$ transporters in astrocytes through activation of LXR, and to stimulate cellular cholesterol efflux (Baldan et al., 2009).

\subsection{Diabetes}

Diabetes mellitus is a disease characterized by hyperglycemia and insufficiency or resistance to insulin. In general, diabetes is associated with increased generation of free radicals, heightened state of oxidative stress, and attenuated antioxidant response. Studies have revealed greater levels of TBARS in the plasma of diabetic patients compared to controls (Kawamura et al., 1994). Plasma lipoproteins isolated from diabetic rats have been shown to be cytotoxic in vitro in cultured cells, suggesting they may have been oxidatively modified in vivo (Morel \& Chisolm, 1989). Other studies have shown that glucose autoxidation and protein glycation can result in the formation of radicals like superoxide anions that promote lipoprotein oxidation.

Hyperglycemia promotes glycation of the protein and lipid components of lipoproteins leading to generation of advanced glycation end-products (AGE) (Sun et al., 2009). Glycation is the process whereby glucose attaches to the $\varepsilon$-amino group of lysines or the $\alpha$ amino group of an $\mathrm{N}$-terminal amino acid in a non-enzymatic manner (Maritim et al., 2003). Biochemically, glucose attachment to the protein results in the formation of an unstable Schiff base, which then rearranges to an Amadori product. These Amadori products then 
undergo dehydration reactions and rearrange themselves to finally form AGE, which are responsible for many of the irreversible pathological effects seen in diabetes. The receptors for AGE (RAGE) are abundantly expressed on vascular endothelial cells, smooth muscle cells and macrophages, which are enhanced in atherosclerotic lesions in diabetes. Since OxLDL has AGE epitopes, it binds RAGE on macrophages and enhances macrophage proliferation and oxidative stress.

Like oxidation, glycation of LDL prevents LDLr-mediated cellular uptake of lipoproteins and promotes scavenger receptor-mediated uptake. In vivo, small, dense, which is more atherogenic than large buoyant LDL, appears to be preferentially glycated; also, in vitro studies suggest that it is more susceptible to glycation (Soran \& Durrington, 2011). Diabetic individuals display higher plasma concentrations of glycated LDL than non-diabetic individuals.

Type 1 diabetes subjects have lipid disorders (diabetic dyslipidemia), with a pro-atherogenic lipid profile: increased concentration of TG and LDL cholesterol, low HDL levels (Verges, 2009). In addition, they display increased cholesterol-triglyceride ratio within their VLDL, increased triglyceride in their LDL and HDL, glycation of apolipoproteins, increased oxidation of LDL and an increase in small dense LDL (relatively more atherogenic). HDL from Type 1 diabetes subjects is less effective in promoting cholesterol efflux and has reduced antioxidant properties.

Subjects with Type 2 diabetes also have a proatherogenic lipid profile with quantitative and qualitative differences in their lipoproteins (Verges, 2005). Typically, they have increased triglyceride levels, increased VLDL production and decreased VLDL catabolism, and decreased HDL cholesterol levels. They have large VLDL particles that are richer in triglyceride, small dense LDL particles, increase in triglyceride content of LDL and HDL, Ox- and glycated-LDL, glycation of apolipoproteins and increased susceptibility of LDL to oxidation.

\section{Concluding remarks}

In conclusion, this chapter has provided a broad overview of the role of oxidative stress, ROS, and lipoprotein oxidation in the pathophysiology of disease states such as atherosclerosis, Alzheimer's disease and diabetes. While Ox-LDL and inflammation seem to be bona fide factors in the development of atherosclerosis, the role of dysfunctional HDL in these disease states is not known at this point. There are several points of uncertainty regarding the in vivo source of ROS and oxidative stress, the physiological behavior of oxidized lipoproteins, particularly in Alzheimer's disease and diabetes, and the line-up of antioxidants and autoantibodies in response to the oxidized factors. It is anticipated that the next decade will provide more insights into the molecular and mechanistic basis of the effect of oxidative damage on lipoprotein in disease states. This would pave the way for new therapeutic options for preventing and treating these diseases. 


\section{Author details}

Vikram Jairam

Yale University School of Medicine, USA

Koji Uchida

Nagoya University, Japan

Vasanthy Narayanaswami

California State University Long Beach, USA

\section{Acknowledgement}

The authors were funded by the Tobacco Related Disease Research Program (TRDRP 17RT0165), the Alzheimer's Association, the National Institutes of Health (NIH-HL096365), CSUPERB Faculty Development Grant and the Drake Family Trust.

\section{References}

Anderson, M. M., Hazen, S. L., Hsu, F. F. \& Heinecke, J. W. (1997). Human neutrophils employ the myeloperoxidase-hydrogen peroxide-chloride system to convert hydroxyamino acids into glycolaldehyde, 2-hydroxypropanal, and acrolein. A mechanism for the generation of highly reactive alpha-hydroxy and alpha,beta-unsaturated aldehydes by phagocytes at sites of inflammation. J. Clin. Invest., Vol. 99, No. 3, (Feb 1997), pp. 424432.

Arai, H., Kashiwagi, S., Nagasaka, Y., Uchida, K., Hoshii, Y. \& Nakamura, K. (1999). Oxidative modification of apolipoprotein $\mathrm{E}$ in human very-low-density lipoprotein and its inhibition by glycosaminoglycans. Arch. Biochem. Biophys., Vol. 367, No. 1, (Jul 1999), pp. 1-8.

Arai, H., Uchida, K. \& Nakamura, K. (2005). Effect of ascorbate on acrolein modification of very low density lipoprotein and uptake of oxidized apolipoprotein e by hepatocytes. Biosci., Biotechnol. Biochem., Vol. 69, No. 9, (Sep 2005), pp. 1760-1762.

Arlt, S., Beisiegel, U. \& Kontush, A. (2002). Lipid Peroxidation in Neurodegeneration: New Insights into Alzheimer's Disease. Curr. Opin. Lipidol., Vol. 13, No. 3, (June 2002), pp. 289-294, 0957-9672

Bailey, J. M., Makheja, A. M., Lee, R. \& Simon, T. H. (1995). Systemic Activation of 15lipoxygenase in Heart, Lung, and Vascular Tissues by Hypercholesterolemia: Relationship to Lipoprotein Oxidation and Atherogenesis. Atherosclerosis, Vol. 113, No. 2, (Mar 1995), pp. 247-258.

Baldán, Á., Bojanic, D. D., \& Edwards, P. A. (2009) The ABCs of sterol transport. J Lipid Res. 2009 April; 50(Supplement): S80-S85

Bassett, C. N., Neely, M. D., Sidell, K. R., Markesbery, W. R., Swift, L. L. \& Montine, T. J. (1999). Cerebrospinal Fluid Lipoproteins Are More Vulnerable to Oxidation in 
Alzheimer's Disease and Are Neurotoxic When Oxidized Ex Vivo. Lipids, Vol. 34, No. 12, (Dec 1999), pp. 1273-1280.

Beauchamp, R. O., Jr., Andjelkovich, D. A., Kligerman, A. D., Morgan, K. T. \& Heck, H. D. (1985). A critical review of the literature on acrolein toxicity. Crit. Rev. Toxicol., Vol. 14, No. 4, (1985), pp. 309-380.

Bergt, C., Pennathur, S., Fu, X., Byun, J., O'Brien, K., McDonald, T. O., Singh, P., Anantharamaiah, G. M., Chait, A., Brunzell, J., Geary, R. L., Oram, J. F. \& Heinecke, J. W. (2004). The myeloperoxidase product hypochlorous acid oxidizes HDL in the human artery wall and impairs ABCA1-dependent cholesterol transport. Proc. Natl. Acad. Sci. (USA), Vol. 101, No. 35, (Aug 2004), pp. 13032-13037.

Berliner, J. A. \& Watson, A. D. (2005). A Role for Oxidized Phospholipids in Atherosclerosis. New Engl. J. Med., Vol. 353, No. 1, (Jul 2005), pp. 9-11.

Björkhem, I., Lütjohann, D., Diczfalusy, U., Ståhle, L., Ahlborg, G. \& Wahren, J. (1998). Cholesterol homeostasis in human brain: turnover of 24S-hydroxycholesterol and evidence for a cerebral origin of most of this oxysterol in the circulation. J. Lipid Res., Vol. 39, No. 8, (Aug 1998), pp. 1594-1600.

Bretillon, L., Sidén, A., Wahlund, L. O., Lütjohann, D., Minthon, L., Crisby, M., Hillert, J., Groth, C. G., Diczfalusy, U. \& Björkhem, I. (2000). Plasma levels of 24Shydroxycholesterol in patients with neurological diseases. Neurosci. Lett., Vol. 293, No. 2, (Oct 2000), pp. 87-90.

Bradamante, S., Barenghi, L., Giudici, G. A. \& Vergani, C. (1992). Free radicals promote modifications in plasma high-density lipoprotein: nuclear magnetic resonance analysis. Free Rad. Biol. Med., Vol. 12, No. 3, (1992), pp. 193-203.

Brown, A. J. \& Jessup, W. (1999). Oxysterols and atherosclerosis. Atherosclerosis, Vol. 142, No. 1, (Jan 1999), pp. 1-28.

Butterfield, D. A. \& Boyd-Kimball, D. (2005). The critical role of methionine 35 in Alzheimer's amyloid beta-peptide (1-42)-induced oxidative stress and neurotoxicity. Biochim. Biophys. Acta, Vol. 1703, No. 2, (Jan 2005), pp. 149-156.

Butterfield, D. A., Bader Lange, M. L. \& Sultana, R. (2010). Involvements of the lipid peroxidation product, HNE, in the pathogenesis and progression of Alzheimer's disease. Biochim. Biophys. Acta, Vol. 1801, No. 8, (Aug 2010), pp. 924-929.

Cyrus, T., Witztum, J. L., Rader, D. J., Tangirala, R., Fazio, S., Linton, M. F. \& Funk, C. D. (1999). Disruption of the 12/15-lipoxygenase gene diminishes atherosclerosis in apo Edeficient mice. J. Clin. Invest., Vol. 103, No. 11, (Jun 1999), pp. 1597-1604.

Daugherty, A., Dunn, J. L., Rateri, D. L. \& Heinecke, J. W. (1994). Myeloperoxidase, a catalyst for lipoprotein oxidation, is expressed in human atherosclerotic lesions. J. Clin. Invest., Vol. 94, No. 1, (Jul 1994), pp. 437-444.

Esterbauer, H., Schaur, R. \& Zollner, H. (1991). Chemistry and Biochemistry of 4hydroxynonenal, Malonaldehyde and Related Aldehydes. Free Rad. Biol. Med., Vol. 11, No. 1, pp. 81-128.

Fang, X., Weintraub, N. L., Rios, C. D., Chappell, D. A., Zwacka, R. M., Engelhardt, J. F., Oberley, L. W., Yan, T., Heistad, D. D. \& Spector, A.A. (1998). Overexpression of 
Human Superoxide Dismutase Inhibits Oxidation of Low-Density Lipoprotein by Endothelial Cells. Circ. Res., Vol. 82, No. 12, pp. 1289-1297, 1524-4571.

Furuhata, A., Ishii, T., Kumazawa, S., Yamada, T., Nakayama, T. \& Uchida, K. (2003). $\mathrm{N}$ (epsilon)-(3-methylpyridinium)lysine, a major antigenic adduct generated in acrolein-modified protein. J. Biol. Chem., Vol. 278, No. 49, (Dec 2003), pp. 4865848665.

Fukai, T., Folz, R. J., Landmesser, U. \& Harrison, D. G. (2002). Extracellular superoxide dismutase and cardiovascular disease. Cardiovasc. Res., Vol. 55, No. 2, (Aug 2002), pp. 239-249.

Garner, B., Witting, P. K., Waldeck, A. R, Christison, J. K, Raftery, M. \& Stocker, R. (1998). Oxidation of high density lipoproteins. I. Formation of methionine sulfoxide in apolipoproteins AI and AII is an early event that accompanies lipid peroxidation and can be enhanced by alpha-tocopherol. J. Biol. Chem., Vol. 273, No. 11, (Mar 1998), pp. 6080-6087.

Haberland, M. E., Olch, C. L., Folgelman, A. M. (1984) Role of lysines in mediating interaction of modified low density lipoproteins with the scavenger receptor of human monocyte macrophages. J. Biol. Chem. 1984 Sep 25;259(18):11305-11311.

Hatters, D.M., Peters-Libeu, C.A., \& Weisgraber, K. H. (2006). Apolipoprotein E structure: insights into function. Trends Biochem. Sci. 31, 445-454.

Hiltunen, T., Luoma, J., Nikkari, T. \& Ylä-Herttuala, S. (1995). Induction of 15-lipoxygenase mRNA and protein in early atherosclerotic lesions. Circulation, Vol. 92, No. 11, (Dec 1995), pp. 3297-3303.

Hoff, H. F. \& O'Neil, J. (1993). Structural and Functional Changes in LDL after Modification with Both 4-hydroxynonenal and Malondialdehyde. J. Lipid Res., Vol. 34, No. 7, (Jul 1993), pp. 1209-1217.

Huang, Y., von Eckardstein, A., Wu, S., Assmann, G. (1995) Effects of the apolipoprotein E polymorphism on uptake and transfer of cell-derived cholesterol in plasma. J. Clin. Invest. 96, 2693-701.

Huang, Y., Weisgraber, K. H., Mucke, L. \& Mahley, R. W. (2004) Apolipoprotein E: diversity of cellular origins, structural and biophysical properties, and effects in Alzheimer's disease. J. Mol. Neurosci. 23, 189-204.

Javitt, N. B. (2008). Oxysterols: novel biologic roles for the 21st century. Steroids, Vol. 73, No. 2, (Feb 2008), pp. 149-157.

Jürgens, G., Hoff, H. F., Chisolm, G. M. 3rd, \& Esterbauer, H. (1987) Chem. Phys. Lipids. Vol. 45 (2-4, (Nov-Dec 1987), 315-336.

Kawamura, M., Heinecke, J. W. \& Chait, A. (1994). Pathophysiological Concentrations of Glucose Promote Oxidative Modification of Low Density Lipoprotein by a Superoxide-dependent Pathway. J. Clin. Invest., Vol. 94, No. 2, (Aug 1994), pp. 771778.

Korotchkina, L. G., Yang, H., Tirosh, O., Packer, L. \& Patel, MS. (2001). Protection by Thiols of the Mitochondrial Complexes from 4-hydroxy-2-nonenal. Free Rad. Biol. Med., Vol. 30, No. 9, (May 2001), pp. 992-999. 
Laukkanen, M. O., Lehtolainen, P., Turunen, P., Aittomäki, S., Oikari, P., Marklund, S. L., Ylä-Herttuala, S. (2000). Rabbit extracellular superoxide dismutase: expression and effect on LDL oxidation. Gene, Vol. 254, No. 1-2, (Aug 2000), pp. 173-179.

Leoni, V. \& Caccia, C. (2011). Oxysterols as Biomarkers in Neurodegenerative Diseases. Chem. Phys. Lipids, Vol. 164, No. 6, (Sept 2011), pp. 515-524.

Levitan, I., Volkov, S. \& Subbaiah, P. V. (2010). Oxidized LDL: diversity, patterns of recognition, and pathophysiology. Antioxid. \& Redox Signaling, Vol. 13, No. 1, (Jul 2010), pp. 39-75.

Lovell, M. A., Xie, C. \& Markesbery, W. R. (2001). Acrolein is increased in Alzheimer's disease brain and is toxic to primary hippocampal cultures. Neurobiol. Aging, Vol. 22, No. 2, (Mar-Apr 2001), pp. 187-194.

Lütjohann, D., Breuer, O., Ahlborg, G., Nennesmo, I., Sidén, A., Diczfalusy, U. \& Björkhem, I. (1996). Cholesterol homeostasis in human brain: evidence for an age-dependent flux of 24S-hydroxycholesterol from the brain into the circulation. Proc. Natl. Acad. Sci. (USA), Vol. 93, No. 18, (Sept 1996), pp. 9799-9804.

Maritim, A. C., Sanders, R. A., \& Watkins, J. B. (2003). Diabetes, Oxidative Stress, and Antioxidants: A Review. J. Biochem. Mol. Toxicol., Vol. 17, No. 1, (Feb 2003), pp. 2438.

McCall, M. R., Tang, J. Y., Bielicki, J. K. \& Forte, T. M. (1995). Inhibition of LecithinCholesterol Acyltransferase and Modification of HDL Apolipoproteins by Aldehydes. Arterioscl. Thromb. Vasc. Biol., Vol. 15, No. 10, (Oct 1995), pp. 15991606.

Meyer, J. \& Schmitt, M.E. (2000). A Central Role for the Endothelial NADPH Oxidase in Atherosclerosis. FEBS Lett., Vol. 472, No. 1, (Apr 2000), pp. 1-4.

Montine, T. J., Huang, D. Y., Valentine, W. M., Amarnath, V., Saunders, A., Weisgraber, K. H., Graham, D. G. \& Strittmatter, W. J. (1996). Crosslinking of apolipoprotein E by products of lipid peroxidation. J. Neuropathol. Exp. Neurol., Vol. 55, No. 2, (Feb 1996), pp. 202-210.

Moore, K. J. \& Tabas, I. (2011) Macrophages in the pathogenesis of atherosclerosis. Cell, 2011 Vol. 145, No 3, (Apr 29), pp. 341-355.

Morel, D. W. \& Chisolm, G. M. (1989). Antioxidant treatment of diabetic rats inhibits lipoprotein oxidation and cytotoxicity. J. Lipid Res., Vol. 30, No. 12, (Dec 1989), pp. 18271834.

Navab, M., Berliner, J. A., Subbanagounder, G., Hama, S., Lusis, A. J., Castellani, L. W., Reddy, S., Shih, D., Shi, W., Watson, A. D., Van Lenten, B. J., Vora, D. \& Fogelman, A. M. (2001). HDL and the inflammatory response induced by LDL-derived oxidized phospholipids. Arterioscl. Thromb. Vasc. Biol., Vol. 21, No. 4, (Apr 2001), pp. 481-488.

Noor, R., Mittal, S. \& Iqbal, J. (2002). Superoxide dismutase--applications and relevance to human diseases. Medical Science Monitor: International Medical Journal of Experimental and Clinical Research, Vol. 8, No. 9, (Sep 2002), pp. 210-215.

Olkkonen, V. M. \& Lehto, M. (2004). Oxysterols and oxysterol binding proteins: role in lipid metabolism and atherosclerosis. Ann. Med., Vol. 36, No. 8, (2004), pp. 562-572. 
Palinski, W., Ylä-Herttuala, S., Rosenfeld, M. E., Butler, S. W., Socher, S. A., Parthasarathy, S., Curtiss, L. K., Witztum, J. L. (1990) Antisera and monoclonal antibodies specific for epitopes generated during oxidative modification of low density lipoprotein, Arteriosclerosis, Vol. 10, No 10 (3) (May-Jun 1990), 325-335.

Perry, G., Cash, A. D. \& Smith, M. A. (2002). Alzheimer Disease and Oxidative Stress. J. Biomed. Biotech., Vol. 2, No. 3, (2002), pp. 120-123.

Refsgaard, H. H., Tsai, L. \& Stadtman, E. R. (2000). Modifications of proteins by polyunsaturated fatty acid peroxidation products. Proc. Natl. Acad. Sci. (USA), Vol. 97, No. 2, (Jan 2000), pp. 611-616.

Reilly, K. B., Srinivasan, S., Hatley, M. E., Patricia, M. K., Lannigan, J., Bolick, D. T., Vandenhoff, G., Pei, H., Natarajan, R., Nadler, J. L. \& Hedrick, C. C. (2004). 12/15Lipoxygenase activity mediates inflammatory monocyte/endothelial interactions and atherosclerosis in vivo. J. Biol. Chem., Vol. 279, No. 10, (Mar 2004), pp. 94409450.

Rifkind, J. M., Abugo, O. O., Nagababu, E., Ramasamy, S., Demehin, A., Jayakumar, R. (2002). Aging and the red cell. Adv. Cell Aging E Geront., Vol. 11, (2002), pp. 283-307.

Rocha, V. Z. \& Libby, P. (2009). Obesity, Inflammation, and Atherosclerosis. Nature Reviews Cardiology, Vol. 6, No. 6, (June 2009), pp. 399-409.

Rosenfeld, M. E., Palinski, W., Ylä-Herttuala, S., Butler, S., \& Witztum, J. L. (1990) Distribution of oxidation specific lipid-protein adducts and apolipoprotein $\mathrm{B}$ in atherosclerotic lesions of varying severity from WHHL rabbits, Arteriosclerosis, Vol. 10, No. 10 (3) (May-Jun 1990), 336-349

Savenkova, M. L., Mueller, D. M. \& Heinecke, J. W. (1994). Tyrosyl radical generated by myeloperoxidase is a physiological catalyst for the initiation of lipid peroxidation in low density lipoprotein. J. Biol. Chem., Vol. 269, No. 32, (Aug 1994), pp. 2039420400.

Schaur, R. (2003). Basic Aspects of the Biochemical Reactivity of 4-hydroxynonenal. Mol. Asp. Med., Vol. 24, No. 4-5 (Aug-Oct 2003), pp. 149-159.

Schippling, S., Kontush, A., Arlt, S., Buhmann, C., Sturenberg, H., Mann, U., MullerThomsen, T. \& Beisiegel, U. (2000). Increased Lipoprotein Oxidation in Alzheimer's Disease. Free Rad. Biol. Med., Vol. 28, No. 3, (Feb 2000), pp. 351-360.

Shao, B., Fu, X., McDonald, T. O., green, P. S., Uchida, K., O’Brien, K. D., Oram, J. F. \& Heinecke, J. W. (2005). Acrolein impairs ATP Binding Cassette Transporter A1dependent cholesterol export from cells through site-specific modification of apolipoprotein A-I. J. Biol. Chem., Vol. 280, No. 43, (Oct 2005), pp. 36386-36396.

Shao, B., Pennathur, S. \& Heinecke, J. W. (2012). Myeloperoxidase Targets apoA-I, the Major High Density Lipoprotein Protein, for Site-Specific Oxidation in Human Atherosclerotic Lesions. J. Biol. Chem., Vol. 287, No. 9, (Feb 2012), pp. 6375-6386.

Shafaati, M., Solomon, A., Kivipelto, M., Björkhem, I. \& Leoni, V. (2007). Levels of ApoE in cerebrospinal fluid are correlated with Tau and 24S-hydroxycholesterol in patients with cognitive disorders. Neurosci. Lett., Vol. 425, No. 2, (Sep 2007), pp. 78-82.

Soran, H. \& Durrington, P. N. (2011). Susceptibility of LDL and its subfractions to glycation. Curr. Opinion in Lipidology, Vol. 22, No. 4, (Aug 2011), pp. 254-261. 
Steinberg, D., Parthasarathy, S., Carew, T. E., Khoo, J. C. \& Witztum, J. L. (1989). Beyond cholesterol. Modifications of low-density lipoprotein that increase its atherogenicity. New Eng. J. Med., Vol. 320, No. 14, (Apr 1989), pp. 915-924.

Sun, L., Ishida, T., Yasuda, T., Kojima, Y., Honjo, T., Yamamoto, Y., Yamamoto, H., Ishibashi, S., Hirata, K. \& Hayashi, Y. (2009). RAGE mediates oxidized LDL-induced pro-inflammatory effects and atherosclerosis in non-diabetic LDL receptor-deficient mice. Cardiovasc. Res., Vol. 82, No. 2, (May 2009), pp. 371-381.

Tamamizu-Kato, S., Wong, J. Y., Jairam, V., Uchida, K., Raussens, V., Kato, H., Ruysschaert, J. M, Narayanaswami, V. (2007). Modification by acrolein, a component of tobacco smoke and age-related oxidative stress, mediates functional impairment of human apolipoprotein E. Biochemistry, Vol. 46, No. 28, (Jul 2007), pp. 8392-8400.

Tórsdóttir, G., Sveinbjörnsdóttir, S., Kristinsson, J., Snaedal, J. \& Jóhannesson, T. (2006). Ceruloplasmin and superoxide dismutase (SOD1) in Parkinson's disease: a follow-up study. J. Neurol. Sci. ., Vol. 241, No. 1-2, (Feb 2006), pp. 53-58.

Uchida, K.,Szweda, L. I., Chae, H-Z., \& Stadtman, E. R. (1993), Immunochemical detection of 4-hydroxynonenal protein adducts in oxidized hepatocytes. Proc. Natl. Acad. Sci. (USA), Vol. 90, No. 18, (Sept 1993), pp. 8742-8746.

Uchida, K., Kanematsu, M., Sakai, K., Matsuda, T., Hattori, N., Mizuno, Y., Suzuki, D., Miyata, T., Noguchi, N., Niki, E. \& Osawa, T. (1998a). Protein-bound acrolein: potential markers for oxidative stress. Proc. Natl. Acad. Sci. (USA), Vol. 95, No. 9, (Apr 1998), pp. 4882-4887.

Uchida, K., Kanematsu, M., Morimitsu, Y., Osawa, T., Noguchi, N. \& Niki, E. (1998b). Acrolein is a product of lipid peroxidation reaction. Formation of free acrolein and its conjugate with lysine residues in oxidized low density lipoproteins. J. Biol. Chem., Vol. 273, No. 26, (Jun 1998), pp. 16058-16066.

Vaya, J. \& Schipper, H. M. (2007). Oxysterols, Cholesterol Homeostasis, and Alzheimer Disease. J. Neurochem., Vol. 102, No. 6, (Sep 2007), pp. 1727-1737.

Vergès B. (2005). New insight into the pathophysiology of lipid abnormalities in type 2 diabetes. Diab. Metab., Vol. 31, No. 5, (Nov 2005), pp. 429-439.

Vergès B. (2009). Lipid disorders in type 1 diabetes. Diab. Metab., Vol. 35, No. 5, (Nov 2009a), pp. 353-360.

Witz, G. (1989). Biological interactions of alpha, beta-unsaturated aldehydes. Free Rad. Biol. Med., Vol. 7, No. 3, (1989), pp. 333-349.

Zarkovic, N. (2003). 4-Hydroxynonenal as a bioactive marker of pathophysiological processes. Mol. Asp. Med., Vol. 24, No. 4-5, pp. 281-291.

Zheng, L., Nukuna, B., Brennan, M. L., Sun, M., Goormastic, M., Settle, M., Schmitt, D., Fu, X., Thomson, L., Fox, P. L., Ischiropoulos, H., Smith, J. D., Kinter, M. \& Hazen, S. L. (2004). Apolipoprotein A-I is a selective target for myeloperoxidase-catalyzed oxidation and functional impairment in subjects with cardiovascular disease. J. Clin. Invest., Vol. 114, No. 4 (Aug 2004), pp. 529-541. 